\title{
Using differentiated teaching to address academic diversity in higher education
}

\author{
Empirical evidence from two cases
}

Matias Thuen Jørgensen and Lena Brogaard

\begin{abstract}
University educators increasingly face groups or classes of students with diverse academic levels, challenging a 'one size fits all' approach to teaching. In this article, we examine whether and how differentiated teaching, especially the concept of student readiness, can be applied to assess and respond to academic diversity, exemplified by two different cases; a methods lecture series and a peer-evaluation seminar. Each case presents specific tools, activities and techniques inspired by differentiated teaching that may be replicated or used for inspiration in similar contexts. The results include better fulfilment of intended learning outcomes, teaching that is perceived to be meaningful by students and educators, and a more inclusive learning environment. The two cases demonstrate the utility of differentiated teaching in higher education, challenging the prevalent assumption that differentiated teaching does not apply well to a university setting.
\end{abstract}

\section{KEYWORDS}

academic diversity, differentiated teaching, higher education, intended learning outcome, readiness

Higher education institutions increasingly face diverse student populations with learners from different backgrounds and with varying educational experience (Boelens et al. 2018; Fry et al. 2008; Ramburuth and McCormick 2001; Tomlinson and Imbeau 2013). In turn, university teachers supervise and instruct students within the same project or course with potentially very different prerequisites for achieving the same learning goals (Boelens et al. 2018; Santangelo and Tomlinson 2009). Ideally, the teacher is able to bring these different competencies into play in a way that adds value to the course 
or project and helps the students achieve the relevant learning outcomes. However, the reality is that in many cases the teacher faces an academically diverse group of students where the gap is too wide. They essentially do not speak the same academic language and have very different prerequisites for understanding and using theory and methods within the given subject. On top of this, the teacher is not necessarily trained to deal with this challenge and has no or limited knowledge of the students' abilities.

The aim of this article is to examine in theory and practice how the pedagogy of differentiated teaching can equip university teachers with the necessary tools and theory to handle academic diversity in groups of students in project supervision or classroom teaching. Differentiated teaching is a pedagogical approach, where teachers provide different avenues for the students to learn the content of the given course, thereby adapting to meet different student needs (Tomlinson 2017). However, the use of differentiated teaching has so far primarily been examined in elementary and secondary education (de Graaf et al. 2019; Ismajli and Imami-Morina 2018). There is thus limited documentation of application in higher education (Boelens et al. 2018; Santangelo and Tomlinson 2009; Turner et al. 2017). A reason for this might be that it is more challenging to apply differentiated teaching principles in higher education because of large class sizes and time constraints, among other factors (Chamberlin and Powers 2010; Ernst and Ernst 2005).

We argue that studies testing the principles of differentiated learning in higher education are necessary, first, exactly because the university classroom differs significantly from primary and secondary schools in terms of academic diversity, physical layout, number of students, teaching style and pedagogy. Second, because the few studies that do exist on differentiated learning in higher education show that it leads to improved learning experiences and outcomes for students (Chamberlin and Powers 2010; Ernst and Ernst 2005; Santangelo and Tomlinson 2009). We thus set out to address the following research question: How can differentiated teaching be used to identify and address academic diversity among university students?

In order to address this research question, we present the results of a differentiated teaching intervention in two cases at Roskilde University in Denmark. Like in other parts of the world, academic diversity has increased in Denmark; the higher education sector has expanded to include more students in general and more students with non-graduate parents in particular. At Roskilde University, this diversity is further pronounced due to an educational structure that builds on the fundamental principles of interdisciplinary 
degrees and problem-oriented project work (Andersen and Heilesen 2015). In practice, this means that the academic staff often teach and supervise groups of students from a variety of subject combinations, such as geography and history, or communications and business studies. Thus, the students do not come only from different (academic) backgrounds. They also acquire different experiences, methods and theoretical knowledge from their various disciplines and departments at the university.

The two cases presented in this article exemplify the challenges that can occur when university teachers either supervise or instruct students at varying academic levels. The first case is a methods course for students, who take up course work in social sciences, either as a part of an interdisciplinary degree or to qualify for a master's programme. The other case is a supervision project module, where students writing projects together are clustered into a larger group with other project teams. In both cases, the authors have experienced challenges that we deem are related to academic diversity. Based on a review of literature on differentiated teaching, we identify relevant pedagogical approaches and tools that we tested in an intervention in both cases to create a better match between student level(s) and the content and process of our teaching and supervision.

The rest of the article is structured as follows. The next section elaborates on the concept and practice of differentiated teaching. In the third section, we present the two cases, as well as problem identification and design of our differentiated teaching intervention. The fourth section presents our results, where we evaluate the intervention and whether our differentiated teaching approach has helped address the identified problems in our cases. Finally, we discuss the potential and challenges of using differentiated teaching at university level.

\section{Differentiated teaching in higher education}

Differentiated teaching is defined in somewhat different ways in the scholarly literature, but the fundamental pedagogy comprises a constructive response to what learners already know (Ismajli and Imami-Morina 2018). Differentiated teaching has been divided into two approaches: divergent, where goals and teaching methods are highly specified to meet the needs of individuals or homogenous groups, and convergent, where all students work on common tasks to achieve common goals (Corno 2008; de Graaf et al. 2019; Deunk et al. 2015). 
Carol Tomlinson and her co-authors have been engaged in academic discussion of differentiation since they introduced the concept in the late 1990s (e.g., Tomlinson et al. 2003; Tomlinson and Imbeau 2013; Tomlinson and Moon 2013; Tomlinson 1999, 2014, 2017). Tomlinson promotes a convergent approach to differentiated teaching as she argues that common goals are a requirement for differentiated learning to happen. She further argues that differentiated learning builds on the interrelationship between three curricular elements. First, content is the input students learn, or in other words what they are taught, and how students access the material. Second, process is how the students learn. Third, the product concerns the output showing what the students have learned. Tomlinson argues that differentiated teaching is effective facilitation because it takes differences between students into account in all three of these curricular elements (Tomlinson 2017).

In line with this understanding, Michelle Chamberlin and Robert Powers (2010) have outlined seven core principles that guide differentiated teaching, which we aimed to follow as we carried out our interventions: (1) Clearly communicated link between curriculum, instruction and (ongoing) assessment that informs about student understanding of material, personal interests and learning profiles. (2) Teachers respond to student differences. (3) Students are challenged at a level that is attainable, through lessons that emphasise critical thinking intended to promote individual growth, while expected to participate in respectful work. (4) Teachers and students collaborate in the learning process. (5) Group work is intermixed with whole class discussions and activities. Student groupings are based on readiness, interests, or learning profiles. (6) The approach to differentiated teaching is proactive rather than reactive. (7) Space, time, and materials are utilised to suit the needs of the various learners (Chamberlin and Powers 2010).

Another key aspect of differentiated teaching that we applied was the use of both conceptual and practical pedagogical tools. Conceptual tools are overarching principles or guidelines that inform application of practical tools (Grossman, Smagorinsky et al. 2000; Grossman, Valencia et al. 1999). Hilary Dack (2019) highlighted Shelley Sherman's (2009) argument that educators oftentimes forget to introduce the conceptual underpinnings behind the implementation of a practical tool. To avoid this, our introduction of practical tools to further differentiated learning will be accompanied by explanations of why these tools are implemented and the goals that we hope to achieve in doing so. 
In order to differentiate, teachers must know the students' levels of readiness in terms of prior knowledge, interests, and learning profiles (Pashler et al. 2009; Tomlinson et al. 2003). Based on this, student readiness emerges as a key concept in differentiated teaching and in our intervention (Pham 2011). However, differentiated teaching does not mean the learning goals should vary for each student depending on their readiness level. Rather, the teacher should acquire information about the students' prior competencies/ knowledge and, based on this information, provide the students with different avenues for achieving the learning goals (Pham 2011).

\section{Research design and methods}

Our study consists of two cases of diverse student groups in undergraduate courses for which the authors of this article are responsible. These cases were chosen (1) because they each represent a primary form of student teacher interaction in higher education, and (2) because we have experienced challenges associated with academic diversity in both cases.

The selected cases are both within social sciences and offered to undergraduate students in the same department, but they vary in regard to class size and format, as summarised in Table 1 . This variation allows us to explore the potential and challenges of selected differentiated teaching approaches in different contexts. We elaborate on the respective challenges associated with the diverse student groups in the subsequent sections.

Table 1. Description of the two cases

\begin{tabular}{|l|l|l|}
\hline & Case 1: Methods course & Case 2: Cluster supervision \\
\hline Format & Class lectures and exercises & Group supervision \\
\hline Size & $80-100$ students & $15-20$ students \\
\hline Department & Social Sciences and Business & Social Sciences and Business \\
\hline Level & Undergraduate & Undergraduate \\
\hline Student diversity & $\begin{array}{l}\text { Very diverse academic back- } \\
\text { grounds and prerequisites }\end{array}$ & $\begin{array}{l}\text { Very diverse academic back- } \\
\text { grounds and prerequisites }\end{array}$ \\
\hline
\end{tabular}




\section{Description of and problem identification in Case 1: Methods course}

The first case is a methods course offered every fall semester. This course is compulsory for students from humanities and natural science who take up course work at the Department of Social Sciences and Business as part of a dual degree, but it can also be an elective course for social science students of, for example, public administration or business studies. The first group often includes students from university colleges or, in a few cases, students who have been in the labour market for some time before continuing their higher education. The composition changes somewhat from year to year. The purpose of the methods course is for the students to learn the most fundamental qualitative and quantitative methods and research designs in social sciences, and to equip the students with practical methodological skills. The course consists of nine lessons that vary from two to four hours.

The learning activities were traditionally a mix of lectures and hands-on exercises. The exercises were sometimes in groups, sometimes individual, where students were instructed to, for instance, formulate questions for a hypothetical survey or identify different types of variables. The examination consisted of a written, home-based exam a few weeks after the last lecture to be completed within forty-eight hours. The content of the course, the readings and the exercises were altered for the intervention, as we describe later on.

Because the students in this course come from other departments or from outside the university, they may have very different levels of experience with and knowledge of methodology. For instance, the humanities students mostly have experience with qualitative methods, while natural science students have more experience with quantitative methods. Moreover, some attend the course solely to fulfil a prerequisite, while others are highly motivated and eager to learn. During previous semesters, we observed and experienced how these differences manifested in several challenges that we assess originate from academic diversity.

\section{Selective and low attendance}

- While all or most of the students showed up to the first lesson, only about half attended the subsequent lessons, and the number fluctuated depending on the theme of the lesson. Based on informal talks with students and an oral evaluation midway through the course, the students seemed to use the teaching plan as a menu to choose from, indicating that many of the students did not find the course relevant as a whole. 
A lack of engagement and activity during lessons

- It proved difficult to engage and activate the students that were present during lectures and exercises. Some expressed that they found the readings and exercises too difficult, others that they found them too easy. Consequently, only a few students participated actively in lectures and group exercises (e.g., by posing questions, displaying enthusiasm and interest, presenting results from group discussions, etc.).

Only a subgroup achieved the learning outcomes

- The student evaluation toward the end of the course showed that those students with a medium level knowledge seemed to learn and benefit from the course, while students at the ends of the spectrum did not.

\section{Description of and problem identification in Case 2: Cluster supervision}

The second case is so-called cluster supervision. Each semester students at Roskilde University earn half of their credits by working on and delivering a group project (normally two to five students in a group). Each project group is assigned a supervisor, who they normally meet with three to four times during the semester to discuss their project and receive feedback. This supervision is supplemented with cluster supervision two times during the semester. In these sessions, three or four project groups are randomly clustered together (normally fifteen to twenty students) and meet in sessions that are moderated and structured by a faculty member.

Prior to the intervention, the learning activities within the cluster sessions consisted of a short presentation by the faculty member on a generic topic of relevance to the project report, such as what should be included in the methods section of the report. The presentation was followed by the students giving each other feedback. All groups submitted their preliminary work on the reports before the cluster session. Additionally, they were expected to prepare thorough feedback for one or two of the other randomly assigned groups. No template for feedback was given to or used by the students.

Due to the way groups are formed and the random combination of groups in the cluster supervision session, the group cluster may be highly diverse in terms of academic level and experience of working together. The students form the project groups on their own with guidance from faculty. In practice, this means that they are formed based on a mix of interest in specific topics, academic ambition, social aspects including friendships, work styles, schedules and necessity, since every student has to be assigned to a group. 
This means that the basis for groups differ; some groups may have been shaped based on academic ambition, while others may have been shaped simply because no other options were available. In addition, some groups may consist of students who have worked together on previous projects, while others may be working together for the first time. The students and the faculty member have no prior knowledge about the other groups, except for a brief project presentation that each group is requested to circulate to the other groups before the session. Based on informal discussions with students and our own observations, we found a number of problems that all relate to academic diversity.

Lack of broad student involvement

- The 'group to group' feedback structure means that each group only receives in depth feedback from one other group. If this feedback is subpar, the takeaway from the session is limited. It is often only the one or two academically strongest or most talkative students from each group who provide feedback. Essentially, the 'group to group' feedback therefore often becomes one-to-one feedback between the strongest and/or most dominant group members.

Lack of purpose and fear of embarrassment

- Challenges emerge when the gap between academically advanced and less academically advanced groups become too wide. Less advanced groups may feel that they have nothing to contribute, may provide feedback that is of little use to the stronger group, or may not be able to absorb the feedback they receive. This may create a lack of purpose for the stronger groups and instances of awkwardness or humiliation for the weaker groups.

Lack of feedback competency

- When feedback is not absorbed by the receiving group, it may also be because students are not pedagogically trained or experienced, or necessarily competent in terms of the difference between 'good' or 'bad' feedback.

Lack of teacher proactiveness

- Teachers have little or no prior knowledge about the students, therefore it is difficult, if not impossible, to be proactive in terms of mitigating the challenges mentioned above. 
Lack of knowledge/recognition of intended learning outcomes (ILOs)

- The students see the only outcome of the sessions as the feedback they receive on their own project. They are rarely aware that a key exercise and take-away comes from giving feedback.

\section{The intervention}

The research design entails an intervention of selected differentiated teaching approaches in both cases to compare their usefulness in addressing similar problems associated with diverse student groups in different contexts. The selection of techniques is based on our problem identification and the literature review, choosing those techniques we believe match or best address the challenges we face. The result is a threefold approach, as illustrated in Figure 1, which takes its point of departure in assessing the students' readiness level. We describe the process and results of the actual intervention in more detail in the results section but provide a brief overview of the selected methods below and in Table 2 .

The baseline for the intervention in both cases is comprised of the challenges identified in the previous sections, which stem from our own experiences and observations from previous semesters along with student evaluations. This design does not provide means for causal inference. Without an experimental design, which has not been feasible in our cases, we cannot determine whether the changes we observe are, in fact, due to our intervention, which is an issue we discuss toward the end of this article.

In Case 1, we distributed a survey to the students prior to the intervention to assess their readiness level. We asked them to rate their level of experience with and to what degree they felt equipped to use ten different qualitative and quantitative methods for collecting and analysing data (e.g., interviews,

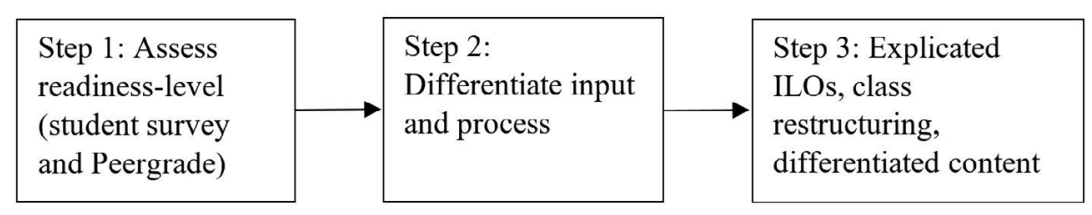

Figure 1. Design of the intervention 
surveys, descriptive statistics), as well as five different research designs. Based on their answers, we applied differentiated teaching in two of Tomlinson's curricular elements: the content of the course (input) and the learning paths (process) we provided the students. We did this by differentiating the in-class exercises, readings and focus of the lectures - we elaborate how in the results section. The differentiation was fully implemented in six out of nine lessons; a colleague that was not involved in the intervention conducted the last three lessons. Hence, the intervention, empirical examples and the results of the intervention refer to the overall planning of the course and the first six out of nine lessons.

Table 2. Teaching activities for the intervention

\begin{tabular}{|l|l|}
\hline Case & Differentiated teaching activities \\
\hline $\begin{array}{l}\text { Case } 1 \\
\text { (methods course) }\end{array}$ & $\begin{array}{l}\text { The lecture topics (methods) were planned based on } \\
\text { the students' experiences as reported in the survey. } \\
\text { Questions and exercises for both the more and less } \\
\text { experienced students are provided for individual and } \\
\text { group discussions. }\end{array}$ \\
$\begin{array}{l}\text { The literature on the curriculum is supplemented by } \\
\text { suggestions for additional readings that approach } \\
\text { the same topic in a different way or provide more } \\
\text { advanced knowledge. }\end{array}$ \\
\hline $\begin{array}{l}\text { Case } 2 \\
\text { (cluster supervision) }\end{array}$ & $\begin{array}{l}\text { Short online video tutorials are provided to help less } \\
\text { experienced students become better acquainted with } \\
\text { the quantitative methods prior to the lessons. }\end{array}$ \\
\hline $\begin{array}{l}\text { Learning outcomes are made explicit from the be- } \\
\text { ginning of the course with specific emphasis on the } \\
\text { value of giving feedback (in addition to receiving it). } \\
\text { Peergrade is used to submit project information and } \\
\text { to give and receive individual feedback prior to the } \\
\text { session. } \\
\text { Introductory content is based on student readiness } \\
\text { levels. } \\
\text { Oral presentation and feedback between groups are } \\
\text { organised based on student readiness, as well as } \\
\text { content and feedback provided prior to the session. } \\
\text { Talking points are prepared for each group based on } \\
\text { readiness level. } \\
\text { End of session reflection between instructor and } \\
\text { student on content, process, and product. }\end{array}$ \\
\hline
\end{tabular}


In Case 2, we used the online tool Peergrade, an online platform to facilitate peer feedback sessions with students, ${ }^{1}$ to achieve the same purpose of assessing student readiness and progress in order to differentiate input and process. Peergrade was used to administer submission of content and feedback among students and makes it possible to create rubrics that convey the learning goals and expectations toward feedback in a more concrete way to the students. The students submit their project reports in Peergrade and are asked to provide feedback via the system. The feedback given is based on predesigned rubrics reflecting the intended learning outcomes. Students provide feedback individually, which allowed us to see the students' level of competency and their ability to provide feedback in order to prepare the cluster supervision (see online supplementary material for survey questions and rubrics) - we further elaborate this in the results section.

\section{Data collection for evaluating the intervention}

To assess the results of the intervention, we use three different types of data that can help us shed light on possible changes in the challenges described earlier.

First, we rely on the students' perception of their own learning outcomes. In Case 1, we repeated the readiness survey after the intervention. Thereby, we can detect any changes in how the students score their degree of experience with the different methods and level of competence before and after the intervention. For Case 2, we reflected with the students in the final cluster session about what they had learned.

Secondly, we rely on our own observations to triangulate the self-evaluations from the students. In both cases, we continuously took observational notes immediately after lectures and cluster sessions. We registered our observations of the students' activity, engagement and participation during the lessons - did they pose and answer questions during whole class sessions or were they predominately silent? Did they give thorough feedback to peers? Furthermore, in Case 1, we registered how many students were present each time.

Finally, the students' output is used to assess their learning progress based on the feedback they gave their peers in Peergrade in Case 2 and the formal student evaluation of the course conducted by the study board in Case 1.

We do not believe that the students' final grades constitute a reliable way of evaluating the results of the intervention. The main reason is that 
attendance in the cluster supervision and methods classes is not compulsory, which means that students can take the exam without participating in the intervention.

\section{Results of the intervention}

In this section, we report how the implementation of the intervention proceeded, and how the described diversity challenges have changed (or not) for Case 1 and Case 2 respectively.

\section{Case 1}

\section{Implementation of the intervention}

The implementation of the intervention in the first case can be categorised into three approaches related to input and process: 'course content based on readiness-assessment', 'differentiation in readings' and 'differentiation in student exercises'.

First, the readiness survey was helpful in planning the course content. The survey identified where the students had varying levels of experience with a method, that is, clear examples of diversity, but also where a majority of the students had similar degrees or lack of experience with a method, which is equally important for course planning. To illustrate, we present a few survey results. For instance, Figure 2 shows that approximately 48 per cent of students agreed that they were already well equipped to conduct surveys prior to the course, whereas the other half disagreed or reported a neutral stance. We saw a similar distribution in responses with respect to document analysis, where half of the students had experience with document studies and the other half did not. Meanwhile, the survey showed that around 90 per cent of the students had none or very little experience with quantitative analyses, such as descriptive statistics (see Figure 3). In contrast, almost 93 per cent of the sixty-seven students that responded had experience with conducting qualitative interviews. ${ }^{2}$

Based on this information, we decided to focus the lectures on those methods where most students had either the least experience or where the students represented the most mixed levels of experience, that is, equipping the students with fundamental skills, especially in surveys, quantitative analysis and document studies. ${ }^{3}$ The information from the survey also implied that previously fixed elements of the course, such as interviews and 


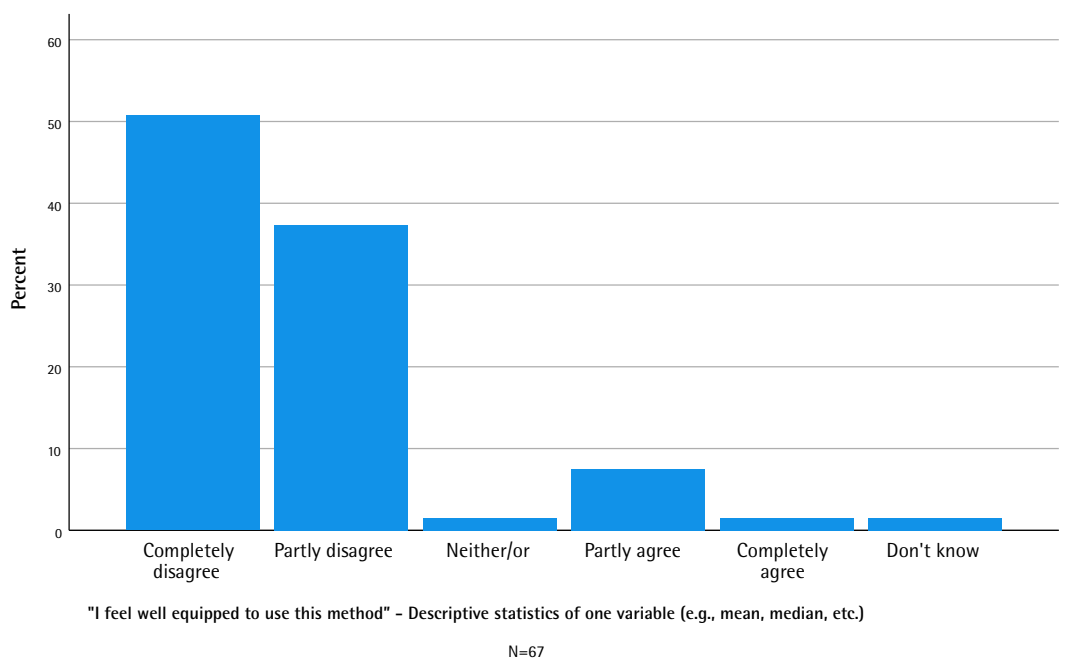

Figure 2. Student self-evaluation of statistical competencies prior to the intervention

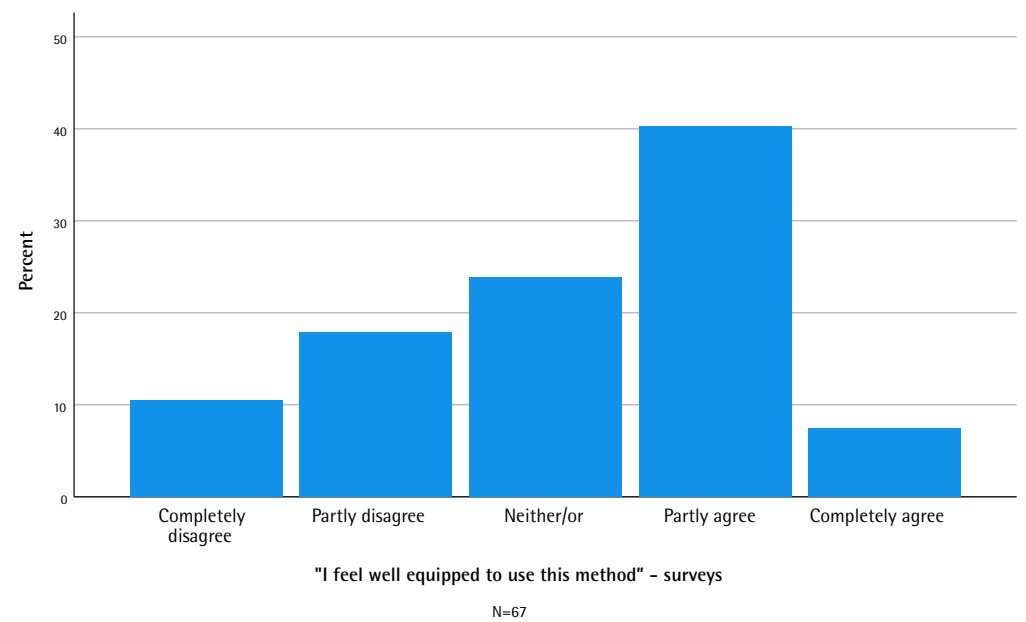

Figure 3. Student self-evaluation of survey competencies prior to the intervention

observational studies, were more or less entirely removed from the lectures (although not from the readings, see below), as most of the students reported feeling well equipped to work with these methods.

Second, we differentiated readings, providing both advanced and less advanced texts on each method along with texts in Danish for those who found the English textbook difficult. The purpose was to provide the students with different avenues for learning the material and going beyond the material in case the students found the mandatory readings insufficient. 
We also provided suggestions for supplemental readings for those students who wished to engage with the course topics at a more advanced level or learn more about methods we did not prioritise in the lessons, for example, interviews and observational studies.

Finally, we differentiated the exercises we gave the students during class by posing mandatory as well as so-called bonus questions. As an example, we asked the students to go through three or four fundamental questions on descriptive statistics, which resembled what they would have to demonstrate for the exam, while a so-called bonus question was more advanced. The purpose was to challenge those students who reported already having experience with a given method in the readiness survey.

We did not base the planning of the course entirely on the readiness survey. First, because students' own perception of their competencies may be an insufficient indicator. Second, because we wanted to ensure a coherent course, which required that a lesson on, for instance, social science research designs was included.

\section{Changes to diversity challenges}

We observed that the first challenge, attendance, improved markedly during the intervention. Almost all the students registered for the course participated in the first lesson and this number remained steady throughout the intervention, as opposed to earlier semesters. Comments in the midway evaluation and final evaluation of the course suggests that the students found the course topics relevant, indicating the usefulness in planning course content informed by the readiness survey.

Secondly, lack of engagement improved as well, compared to previous semesters. From our own observations, the students were much more active and committed during lessons. We noted an increase in the number of relevant questions to the teacher during plenary sessions, lively student discussions during group exercises, and their presentations of group discussions and exercises demonstrated that they were taking the task seriously. The presentations also revealed that some groups had time to complete the bonus questions, whereas other groups had only or barely finished the mandatory questions, demonstrating the usefulness in providing different levels of exercises. During the midway evaluation, students expressed that the group exercises in general were very beneficial, as it helped them internalise the curriculum. Furthermore, they remarked that the supplemental readings were helpful, especially for those who considered the textbook too difficult. 
The change in attendance and engagement also suggests that they felt challenged enough by the curriculum and exercises to stay engaged, giving them an incentive to show up for class and participate actively, but not so challenged that they became detached. This observation is substantiated by the midway evaluation, which shows that the six lessons included in the intervention were perceived as academically challenging, but that it was possible to keep up based on readings, lessons and exercises. However, both in the midway and final evaluations, some students noted that the course was very (and perhaps too) compact, as the course covered a lot of material within a limited number of lessons.

Finally, the third challenge, that only a subgroup of students achieve the learning outcomes, seemed to change for the better. After the intervention, the study board's evaluation of the course showed increased satisfaction with the academic level and curriculum. The readiness survey, which we repeated after completing the intervention, also showed that there was progress in the students' self-evaluation of competencies. For instance, Figure 4 illustrates that approximately 55 per cent of students reported feeling well equipped to conduct descriptive statistics after completing the course, compared to approximately 10 per cent prior to the course (Figure 2).

Figure 5 shows that after the intervention the percentage of students that feel well equipped to conduct surveys increased to almost 82 per cent, compared to the very mixed levels of self-reported survey competencies prior to the intervention, see Figure 3.

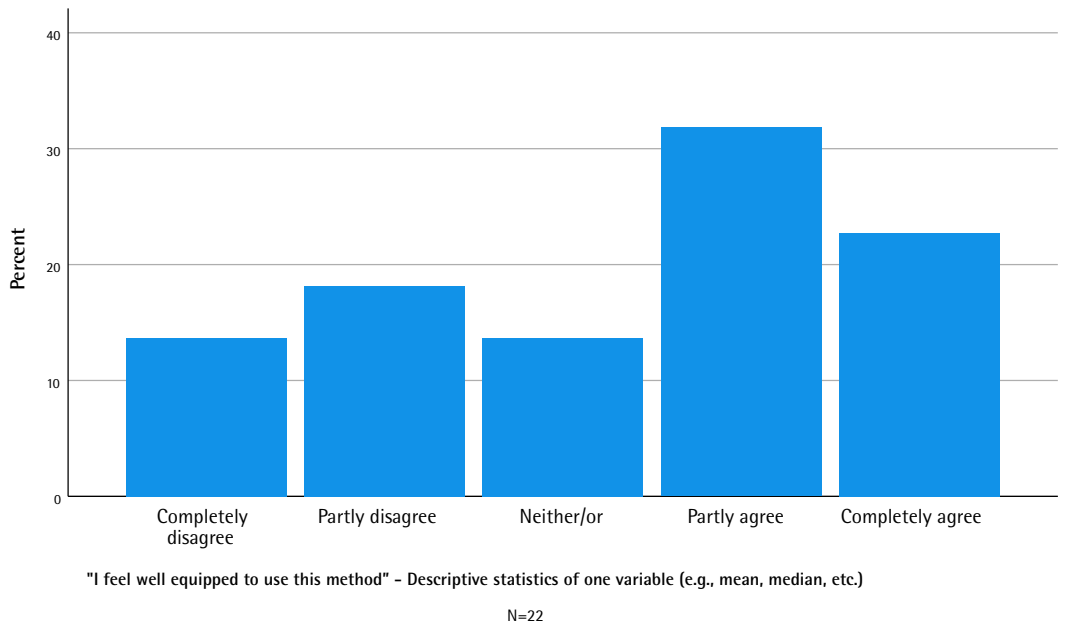

Figure 4. Student self-evaluation of statistical competencies after the intervention 


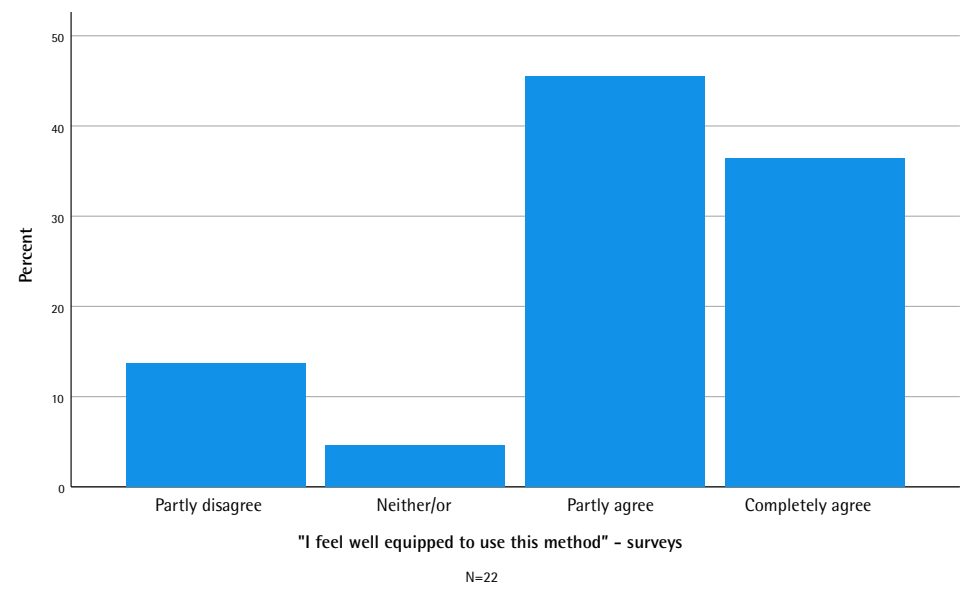

Figure 5. Student self-evaluation of survey competencies after the intervention

However, the post-intervention survey responses come with great uncertainty and should be interpreted with caution. Only twenty-two completed the survey after the intervention, making the post-intervention survey responses much less representative and potentially biased. The drop in response rate could be due to general course fatigue, that they were engaged in exams at this point and survey overload, as the students also had to fill out an evaluation of the course from the study board.

\section{Case 2}

Implementation of the intervention

The implementations made as part of the intervention can be categorised into three aspects: 'explication of learning outcomes', 'session restructuring based on ILOs and student feedback' and 'differentiation based on readiness assessment'.

First, we explicated the learning outcomes by providing the students with a written introduction to the cluster session. This contained access to the Peergrade system and instructions that each group should submit a brief introduction to their project, while each individual student should provide feedback to one randomly assigned group based on a rubric. It also contained detailed information about the ILOs for the session. It was articulated that the purpose of the session is threefold: '(1) A chance to learn by giving other students feedback (it is empirically proven that students learn more from 
giving feedback than from receiving it); (2) A place to get inspiration for your own project; and (3) A place to get feedback on your project'. Finally, the students were instructed to consider how they provide feedback and given information about what can be considered 'good' and 'bad' feedback.

Second, we restructured the session, based on the ILOs and the student feedback collected through Peergrade. As mentioned, the cluster sessions had previously been based on oral group-to-group feedback, which in practice meant that each group often only received in-depth feedback from one other group. With the intervention, students were required to provide individual feedback, rather than group feedback, which meant that each group received in-depth written feedback from an average of three different, randomly selected, individuals. The starting point for the session in the intervention is the written feedback as well as the explicit change in focus from what can be gained by receiving feedback to also include what can be gained from giving it.

During the intervention, the session progressed as follows: The students were given a brief introductory 'lecture'. The student groups each gave a brief (three to five minute) presentation of their project idea. The student groups were asked to read the written feedback they had received, discuss and evaluate it, and answer the following questions:

1. What are three aspects of the feedback that were useful to you (why?)

2. What were feedback elements that were less useful (why)?

3. How will you change your project after this discussion?

This was followed with a discussion in plenum. Instead of using this time to present direct oral feedback to the other groups, the groups were asked to present and reflect on their answers to the questions above, while the other groups were asked to reflect and comment on these answers.

Third, our access to the students' project introductions and individual feedback prior to the session allowed us to assess general, group and individual level of competency and ability to provide feedback. We used this information to inform the contents of the initial 'lecture' and to design talking points for each group. We designed the talking points by reading and comparing the submitted project introductions and the written feedback from other students. Talking points could, for example, ask students to reflect on their chosen methods, theoretical choices, and more. In cases where we found a good alignment between the level/quality of the content compared 
to the feedback given, no or few talking points were provided. In cases where the feedback was not adequate or indicated a gap in academic level between the content and feedback, we added more talking points. Each student group was provided with a customised handout containing the feedback they had received from other students and the talking points we had prepared. They were then asked to discuss and evaluate the feedback and to reflect on what relevant changes they should make to their project based on the feedback and the talking points. Because each student group received a customised handout and only saw their own talking points, they were not aware of which and how many talking points other groups had received. This meant that in instances of marked academic diversity - where the gap between content and feedback quality was too wide - the talking points could fill the gap, without the students' awareness. In doing so, the student groups were each addressed at their level, while avoiding an obvious division into 'strong' and 'weak' students.

\section{Changes to diversity challenges}

We addressed the lack of knowledge/recognition of ILOs by being more explicit about the benefits and learning outcomes of giving feedback and by restructuring the sessions to also focus on evaluation of the feedback given. We observed that this changed the students' focus from exclusively how to improve their own project to also include the act of giving feedback. While this focus, in and of itself, did not vastly improve the students lack of feedback competency, the awareness of the importance of giving 'good' feedback, combined with improved knowledge of what constitutes 'good' feedback meant that students were more careful and constructive in their feedback delivery. This resulted not only in better feedback but also in an improved atmosphere among the students. Specifically, the improved atmosphere meant that there were no awkward or uncomfortable situations provoked by differences in academic level, when compared to similar sessions in previous years.

We addressed the lack of teacher proactiveness, through use of Peergrade to collect project presentations and feedback on these from students before the session. This allowed us to assess student readiness and act proactively to prevent potential diversity challenges. A key tool in doing so were the talking points, which were added to the feedback each group received. When evaluating the session, students specifically highlighted these as very useful, and we observed that the talking points silently limited the gap between 
students, as they all had points to discuss and were challenged at their own academic level. This, combined with the improved atmosphere mentioned above, contributed significantly to address the lack of purpose and fear of embarrassment that some students had felt. Finally, individual rather than group-based feedback addressed the lack of broad student involvement. The most talkative students would still dominate discussions at the sessions, but since all discussion was based on the written individual feedback, it was impossible not to involve perspectives from all students to some extent.

\section{Discussion and conclusion: Potentials and challenges in using differentiated teaching in higher education}

This article has demonstrated how differentiated teaching, especially pertaining to student readiness assessment and response, can be applied to address academic diversity in a higher education context. The results of such implementation include better fulfilment of intended learning outcomes, teaching that is perceived to be meaningful by students at varying academic levels, and a more inclusive learning environment. While the two cases represent typical student-teacher interactions in higher education, the difference in context and approach of the two cases begs the question of what more general lessons we can draw about the use of differentiated teaching.

Across our two cases, the variety of differentiated teaching approaches tested to address academic diversity in the two cases have proven useful. Specifically, the two cases demonstrate that assessing the students' readiness level is a strong tool in a university setting. It provides the teacher with important knowledge about the experience and competencies of a group of students that makes it possible to proactively improve the process of teaching and supervising.

Moreover, each of our two cases have resulted in concrete and tested tools for assessing readiness in higher education that other university teachers can use and adjust to match their own classes and supervision: a survey questionnaire and rubrics. ${ }^{4}$ The two cases can also be seen as a catalogue of ideas for how to differentiate the teaching, for example, providing customised talking points for feedback, varying the levels of student exercises and readings and planning lecture themes to match student experience.

There are two obvious counterarguments against using differentiated teaching in a university setting that need to be discussed in light of our findings. The first counterargument is that practicing differentiated teaching 
requires close interaction with and getting to know the students. For this reason, differentiated teaching has primarily been applied successfully in elementary and secondary education (de Graaf et al. 2018; Ismajli and ImamiMorina 2018). This is not possible for university teachers with large student populations and few contact hours (Ernst and Ernst 2005). However, the techniques we have applied in our two case studies for assessing student readiness - a short electronic survey for large groups of students and student feedback in Peergrade for smaller groups of students - do not require close and continued interaction. The two tools make it possible to gain the necessary readiness information from the students in a more anonymous and aggregated way that allows for planning variation in learning paths.

Second, we acknowledge that differentiated teaching requires an extra effort, which can pose a challenge to university teachers, where teaching is only one among several other tasks. Our two cases show how to make it manageable. Inspired by Chamberlin and Powers (2010), we have started out small, focusing on a few relevant approaches rather than a revolutionary approach. It takes a relatively short time to prepare, collect and process the readiness information that the students provide electronically ahead of class. In many instances, the rubrics used in Peergrade and the questions developed for the survey can be re-used each semester for the same course or type of supervision. With regard to differentiating the teaching process, we have done this as a part of the normal task of preparing for class and supervision. However, the information from the readiness assessment might call for some changes from semester to semester. For instance, in the methods course, the readiness information from next semesters' student group might require smaller changes in the level of student exercises as the composition of students change. In the cluster supervision case, it will be necessary to read not only the students' submitted materials but also their feedback to each other to prepare differentiated talking points.

Our results should be used and interpreted with caution. We did not apply an experimental design and have no control group to compare with. In other words, although we believe that the changes we observed are a result of the differentiated teaching techniques, we cannot prove with complete certainty that this is the case. Moreover, although we strived to triangulate our results with different types of data, it is difficult to draw any firm conclusions based on survey data, student evaluations and the authors' own observations. We thus encourage more scholars to test our techniques and other differentiated 
teaching approaches to further our knowledge on the validity and applicability of this pedagogy in a university setting. The goal of this study was to test how similar base principles of differentiated teaching can be successful in addressing diversity challenges in vastly different contexts. Future studies may also test various differentiation approaches, principles and tools in additional similar contexts to determine specific utility in specific situations.

Despite these limitations, we found that we as teachers and the students benefitted from the introduction of differentiated learning principles in many ways. For instance, the students were generally much more engaged compared to previous semesters. This benefits both teachers and students, resulting in more students achieving the learning outcomes and smoother sessions characterised by motivated students and a positive atmosphere. When faced with academically diverse groups of students, differentiated teaching has the potential to produce positive results that outweigh the added costs (Chamberlin and Powers 2010; Ernst and Ernst 2005; Santangelo and Tomlinson 2009; Turner et al. 2017). Thus, our findings demonstrate the utility of differentiated teaching in higher education, challenging the prevailing assumption that differentiated teaching does not apply well to a university setting.

\section{Acknowledgments}

We would like to highlight that the two authors contributed equally to the study and the article. Sincere thanks to Professor Eva Bendix Petersen whose expert knowledge was essential to the study.

Matias Thuen Jørgensen is Assistant Professor in the Department of Social Sciences and Business, Roskilde University, Denmark. Matias's research mainly focuses on the tourism phenomenon and sector. He teaches marketing management and supervises students enrolled in business programmes at both the master and bachelor level. He continuously works to develop and refine his pedagogical approach. E-mail: matiastj@ruc.dk 


\section{Matias Thuen Jørgensen and Lena Brogaard}

Lena Brogaard is Associate Professor in the Department of Social Sciences and Business, Roskilde University, Denmark. Lena's research focuses on public-private collaboration and contracting out. She teaches and supervises undergraduate and graduate students in quantitative methods, evidence and performance measurement in the public sector as well as marketisation. She is continuously working to develop her teaching strategies and pedagogical approach to enhance student learning. E-mail: brogaard@ruc.dk

\section{Notes}

1. See Peergrade, https://www.peergrade.io/ (accessed 28 May 2021).

2. Figures and data for this statement and other responses on particular methods can be retrieved by contacting the authors. They have been excluded here to avoid an overload of figures.

3. Document studies constituted the last three out of the nine lectures, which were not a part of the intervention, as explained in the methods section. The readiness survey was used to decide on including that particular method in the course as part of the overall planning, but we do not evaluate on the results of these lessons.

4. Available from authors.

\section{References}

Andersen, A. S. and S. B. Heilesen (2015), The Roskilde Model: Problem-Oriented Learning and Project Work (Cham: Springer International Publishing).

Boelens, R., M. Voet and B. D. Wever (2018), 'The design of blended learning in response to student diversity in higher education: Instructors' views and use of differentiated instruction in blended learning', Computers \& Education 120: 197-212. https://doi.org/ 10.1016/j.compedu.2018.02.009.

Chamberlin, M. and R. Powers (2010), 'The promise of differentiated instruction for enhancing the mathematical understandings of college students', Teaching Mathematics and Its Applications 29, no. 3: 113-139. https://doi.org/10.1093/teamat/ hrq006.

Corno, L. (2008), 'On teaching adaptively', Educational Psychologist 43, no. 3: 161-173. https://doi.org/10.1080/00461520802178466.

Dack, H. (2019), 'The role of teacher preparation program coherence in supporting candidate appropriation of the pedagogical tools of differentiated instruction', Teaching and Teacher Education 78: 125-140. https://doi.org/10.1016/J.TATE.2018.11.011. 
de Graaf, A., H. Westbroek and F. Janssen (2018), 'A practical approach to differentiated instruction: How biology teachers redesigned their genetics and ecology lessons', Journal of Science Teacher Education 30, no. 1: 6-23. 10.1080/1046560X.2018.1523646.

Deunk, M., S. Doolaard, A. Smale-Jacobse and R. Bosker. (2015), Differentiation within and across Classrooms: A Systematic Review of Studies into the Cognitive Effects of Differentiation Practices (Groningen: GION, University of Groningen).

Ernst, H. R. and T. L. Ernst (2005), 'The promise and pitfalls of differentiated instruction for undergraduate political science courses: Student and instructor impressions of an unconventional teaching strategy', Journal of Political Science Education 1, no. 1: 39-59. https://doi.org/10.1080/15512160590907513.

Fry, H., S. Ketteridge and S. Marshall (2008), A Handbook for Teaching and Learning in Higher Education: Enhancing Academic Practice, 3rd ed. (New York: Routledge).

Grossman, P. L., P. Smagorinsky and S. Valencia (1999), 'Appropriating tools for teaching English: A theoretical framework for research on learning to teach', American Journal of Education 108: 1-29. https://doi.org/10.2307/1085633.

Grossman, P. L., S. Valencia, K. Evans, C. Thompson, S. Martin and N. Place (2000), 'Transitions into teaching: Learning to teach writing in teacher education and beyond', Journal of Literacy Research 32, no. 4: 631-662. https://doi.org/ 10.1080/10862960009548098.

Ismajli, H. and I. Imami-Morina (2018), 'Differentiated instruction: Understanding and applying interactive strategies to meet the needs of all the students', International Journal of Instruction 11, no. 3: 207-218. https://doi.org/10.12973/iji.2018.11315a.

Pashler, H., M. Mcdaniel, D. Rohrer and R. Bjork (2009), 'Learning styles concepts and evidence', Psychological Science in the Public Interest 9, no. 3: 105-119. https://doi.org/ 10.1111/j.1539-6053.2009.01038.x.

Pham, H. L. (2011), 'Differentiated instruction and the need to integrate teaching and practice', Journal of College Teaching \& Learning (TLC) 9, no. 1: 13-20. https://doi.org/ 10.19030/tlc.v9i1.6710.

Ramburuth, P. and J. McCormick (2001), 'Learning diversity in higher education: A comparative study of Asian international and Australian students', Higher Education 42 no. 3: 333-350. https://doi.org/10.1023/A:1017982716482.

Santangelo, T. and C. A. Tomlinson (2009), 'The application of differentiated instruction in postsecondary environments: Benefits, challenges, and future directions', International Journal of Teaching and Learning in Higher Education 20, no. 3: 307-324.

Sherman, S. C. (2009), 'Haven't we seen this before? Sustaining a vision in teacher education for progressive teaching practice', Teacher Education Quarterly 36, no. 4: 41-60. https://doi.org/10.2307/23479283.

Tomlinson, C. A. (1999), The Differentiated Classroom: Responding to the Needs of All Learners (Alexandria, VA: Association for Supervision and Curriculum Development). 


\section{Matias Thuen Jørgensen and Lena Brogaard}

Tomlinson, C. A. (2014), The Differentiated Classroom: Responding to the Needs of All Learners, 2nd ed. (Alexandria, VA: Association for Supervision and Curriculum Development).

Tomlinson, C. A. (2017), How to Differentiate Instruction in Academically Diverse Classrooms (Alexandria, VA: Association for Supervision \& Curriculum Development).

Tomlinson, C. A., C. Brighton, H. Hertberg, C. M. Callahan, T. R. Moon, K. Brimijoin, L. A. Conover and T. Reynolds (2003), 'Differentiating instruction in response to student readiness, interest, and learning profile in academically diverse classrooms: A review of literature', Journal for the Education of the Gifted 27, no. 2-3: 119-145. https://doi.org/10.1177/016235320302700203.

Tomlinson, C. A. and M. B. Imbeau (2013), 'Differentiated instruction', in B. J. Irby, G. Brown, R. Lara-Alecio and S. Jackson (eds), The Handbook of Educational Theories (Charlotte, NC: Information A), 1097-1117.

Tomlinson, C. A. and T. R. Moon (2013), Assessment and Student Success in a Differentiated Classroom (Alexandria, VA: Association for Supervision and Curriculum Development).

Turner, W. D., O. J. Solis and D. H. Kincade (2017), 'Differentiating instruction for large classes in higher education', International Journal of Teaching and Learning in Higher Education 29, no. 3: 490-500. 